\title{
Laboreal
}

Volume 4 N$^{\circ} 2$ | 2008

A inovação

\section{A integração das necessidades de usuários e projetistas como fonte de inovação para o projeto}

La integración de las necesidades de usuarios y proyectistas como fuentes de innovación para el proyecto

L'intégration des besoins des utilisateurs et des concepteurs comme source de l'innovation dans la conception

The integration of the needs of users and designers as a source of innovation for the project

Francisco Duarte, Carolina Conceição, Cláudia Cordeiro e Francisco Lima

\section{(2) OpenEdition}

Journals

Edição electrónica

URL: http://journals.openedition.org/laboreal/11269

DOI: 10.4000/laboreal. 11269

ISSN: 1646-5237

Editora

Universidade do Porto

Refêrencia eletrónica

Francisco Duarte, Carolina Conceição, Cláudia Cordeiro e Francisco Lima, « A integração das necessidades de usuários e projetistas como fonte de inovação para o projeto », Laboreal [Online], Volume $4 \mathrm{~N}^{\circ} 2$ | 2008, posto online no dia 01 dezembro 2008, consultado o 10 outubro 2019. URL : http://journals.openedition.org/laboreal/11269; DOI : 10.4000/laboreal.11269

Este documento foi criado de forma automática no dia 10 outubro 2019.

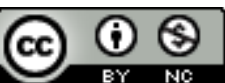

Laboreal está licenciado com uma Licença Creative Commons - Atribuição-NãoComercial 4.0 Internacional. 


\section{A integração das necessidades de usuários e projetistas como fonte de inovação para o projeto}

La integración de las necesidades de usuarios y proyectistas como fuentes de innovación para el proyecto

L'intégration des besoins des utilisateurs et des concepteurs comme source de l'innovation dans la conception

The integration of the needs of users and designers as a source of innovation for the project

Francisco Duarte, Carolina Conceição, Cláudia Cordeiro e Francisco Lima

\section{NOTA DO EDITOR}

Manuscrito recebido em : Setembro/2008

Aceite após peritagem em : Novembro/2008

\section{Introdução}

1 A associação entre inovação e usuários vem sendo evidenciada já há algum tempo. Hippel (1988) aponta o usuário como a fonte principal do processo de inovação tecnológica. Esse autor estudou as fontes de inovação no desenvolvimento de produtos e suas pesquisas evidenciaram que o: "lócus of almost the entire innovation process is centered on the user" (Hippel, 1988, p. 27). Esse resultado, de acordo com o autor, estaria em desacordo ou em conflito com a visão convencional e com a literatura prescritiva da área de desenvolvimento de produtos. Essa literatura considerava que as fontes de inovação estariam presentes, quase que exclusivamente, no interior das empresas fabricantes dos produtos, raramente estabelecendo relações entre inovações 
e usuários dos produtos. Este artigo, também, trata da contribuição dos usuários para as soluções inovadoras. No entanto, a ênfase está na articulação entre necessidades de usuários e necessidades dos projetistas das diferentes especialidades envolvidas na concepção dos espaços de trabalho. A reflexão a posteriori sobre o projeto de um novo centro de controle de dutos [3] de distribuição de gás e óleo mostra que as soluções dos problemas de concepção desse espaço de trabalho emergiram da compatibilização e integração, muitas vezes conflituosas, entre as necessidades dos diferentes usuários e projetistas.

2 O projeto arquitetônico é um processo de antecipação e idealização da realidade desejada (Boutinet, 2002). A execução do projeto (obra) é a transformação do abstrato idealizado em realidade concreta, onde, por diversas vezes, a solução projetada inicialmente é reconcebida (Cordeiro, 2003). O processo de projeto é organizado segundo idéias e princípios que, na prática, evoluem e se transformam.

3 Uma primeira idéia bastante comum é que o programa arquitetônico define com precisão o problema colocado pelo cliente, que será, em seguida, resolvido pelos projetistas. Contudo, o programa não é totalmente definido no momento de formalização da demanda [4] pelo cliente. Basta lembrar que nem sempre o cliente ou seu interlocutor é o usuário direto do espaço. Ao longo do processo de concepção há uma construção progressiva do programa pelos atores envolvidos a fim de garantir sua coerência com as necessidades do projeto, da obra e de sua utilização (Martin, 2000 ; Cordeiro, 2003). Os resultados finais, em termos de qualidade, custo e funcionalidade do espaço, dependem da integração dos diferentes pontos de vista - clientes, usuários, projetistas, responsáveis pela execução da obra e demais envolvidos ao longo do processo. Quando se trata, em especial, de espaços para o trabalho coletivo, são diversos os usuários - diretores, gerentes, funcionários fixos e/ou temporários, ligados ou não à atividade principal do espaço - aumentando a necessidade de integração de suas demandas para a ampliação da abrangência do programa e, consequentemente, das possibilidades de êxito do projeto. Até mesmo a presença virtual de visitantes ocasionais ganhou um papel determinante no caso aqui relatado, uma vez que a sala de controle funciona como espaço vitrine da imagem de excelência da empresa.

Outra idéia comum é que, dado um projeto arquitetônico, os demais projetistas "farão a sua parte", ou seja, os projetos complementares (estrutura, instalações elétrica e hidrosanitárias, climatização etc.) seguirão as definições do projeto arquitetônico. Na prática, observa-se que o projeto arquitetônico tem que ser modificado em várias situações, e algumas soluções iniciais são até mesmo inviabilizadas em função das demandas oriundas dos demais projetos complementares. Vários problemas originados por essa dinâmica poderiam ser antecipados com a promoção de interações entre os projetistas desde a fase inicial do projeto, o que se tem procurado fazer por meio de técnicas diversas de compatibilização de projetos, dos sofisticados recursos informatizados de representação tridimensional às equipes multiprofissionais de coordenação, passando por técnicas como o QFD - Quality Function Deployment (Vanni, 1999 ; Silva, 2000).

5 Por fim, é ainda comum reservar "a atividade de concepção" exclusivamente à fase de projeto e à atividade dos projetistas profissionais. De modo geral, reconhece-se muito pouco a contribuição da execução da obra para a concepção. Assim como acontece na organização do trabalho industrial, prevalece uma visão que separa concepção de execução : as atividades de definições de requisitos, de elaboração do projeto conceitual 
e de representação da solução do problema, onde se exerce a criatividade, seriam exclusivas da fase de concepção do espaço; a execução é vista como uma mera sequência de ações pré-estabelecidas para "fabricá-lo", onde tudo que é essencial já foi decidido e definido. A obra é vista usualmente como uma simples etapa de "montagem", na qual "basta seguir o projeto detalhado". Na prática, verifica-se que inúmeros aspectos do projeto são realmente definidos e muitas vezes detalhados durante a obra.

6 Em suma, a construção física do espaço de trabalho depende da construção social (Daniellou, 2004, 2007) do projeto, pela qual se estabelecem relações de cooperação, comunicação e diálogo, que permitem em momentos diversos a confrontação de pontos de vista e necessidades dos diversos agentes. Este artigo trata de algumas questões colocadas pela construção social do processo de projeto, tomando como base a intervenção ergonômica para concepção de um centro de controle. Esta intervenção teve início desde os estudos preliminares, passando por todo o projeto, até a etapa de execução da obra. Mais especificamente, será mostrado que o processo projetual de fato se estende do projeto inicial à execução da obra, evidenciando como o desejável, o possível e o necessário se influenciam para dar forma ao espaço construído. 0 que, de início, é desejado pelos agentes envolvidos no projeto, transforma-se diante de necessidades reconhecidas e legitimadas ao longo do processo de concepção do espaço. Da confrontação entre os agentes, que incorporam certas necessidades e pontos de vista, emergem possibilidades concretas que dão forma ao espaço. Em um processo de "duas mãos", assim como o confronto com a objetividade material e social muda as vontades manifestadas e lhes dá uma forma definida, também as necessidades subjetivamente ressentidas em relação ao espaço conformam a realidade a ser transformada.

\section{A abordagem metodológica e a intervenção ergonômica}

7 A abordagem metodológica utilizada para descrever o processo de projeto do centro de controle, aqui apresentado, pode ser caracterizada como uma reflexão a posteriori da intervenção ergonômica. Ela tem como base as pesquisas sobre a prática profissional descritas por Schön (1983). Trata-se de uma abordagem reflexiva e sistemática da intervenção ocorrida durante as etapas de um projeto a fim de se evidenciarem aspectos da atividade real. Segundo Schön, na maior parte de suas vidas profissionais, os arquitetos, médicos, engenheiros e outros especialistas não podem simplesmente aplicar conhecimentos e técnicas oriundos das ciências, da maneira como eles aprendem em sua formação universitária, que se baseia fortemente no modelo da racionalidade técnica (Daniellou, 1988). Na realidade, a competência dos profissionais seria oriunda de sua capacidade de refletir durante e sobre as situações que eles enfrentam no seu dia-a-dia, o que levou Schön (1983) a construir o modelo da prática reflexiva.

8 A partir do estudo de caso descrito por Conceição (2007), buscou-se extrair questões que pudessem alimentar a reflexão sobre o processo projetual e, eventualmente, contribuir para a produção de conhecimento científico. 0 objetivo não é particularizar este caso ressaltando as especificidades que o tornam um projeto único, mas sim buscar a generalização de certos aspectos que possam dialogar com teorias de projeto. Cada 
caso é único e necessita de uma abordagem própria para ajustar a concepção do espaço ao seu contexto material, institucional e de uso ; no entanto, os métodos usados em um projeto são generalizáveis no sentido de que podem ser adicionados a um repertório de conhecimentos, valores e métodos (Granath, 1991). Dessa forma, após a participação dos autores no projeto mencionado, a experiência suscitou reflexões em torno da prática profissional. Para isso procurou-se registrar um conjunto de traços materiais de forma a se manter a memória da intervenção, sendo eles: os relatórios, memoriais descritivos, desenhos e demais documentos oficiais do projeto, o caderno de campo da intervenção, as atas de reuniões, e os correios eletrônicos. A descrição e reconstituição da intervenção foram confrontadas e validadas junto a outros membros da equipe de projeto e ao chefe de projeto da empresa, o que permitiu enriquecer o relato e, em particular, os motivos das transformações e evoluções ocorridas no decorrer do projeto.

9 Ao privilegiar a atividade como objeto de estudo, o espaço de trabalho é, para a ergonomia, um meio de realização das atividades de trabalho que deve ser projetado de forma a favorecer o seu desenvolvimento. Para a arquitetura, a concepção de um espaço deve, entre outros objetivos, favorecer o seu uso, o que reforça a importância de se identificarem as necessidades dos usuários. Assim, um dos objetivos do trabalho em conjunto de arquitetos e ergonomistas nos projetos seria o de alimentar o processo de projeto com informações que permitam a compreensão do que realmente está em jogo no projeto, a partir da caracterização das atividades de trabalho (Martin, Ledoux, Escouteloup \& Daniellou,1995). Não se trata simplesmente de aumentar a quantidade de informação a ser considerada no projeto, mas de integrar as necessidades de usuários e projetistas.

10 A intervenção ergonômica utilizada neste projeto foi baseada na abordagem da atividade futura (Daniellou, 1992, 2005). O principal papel dos ergonomistas foi tentar fazer com que as decisões fossem guiadas por uma reflexão sobre o trabalho futuro, contemplando: a análise de situações de referência, a identificação de situações características e as simulações do trabalho futuro. Essa abordagem requer uma estruturação da participação dos usuários, com a previsão de um acompanhamento das diversas fases do projeto por eles.

11 Através da análise ergonômica do trabalho (AET), onde se deu prioridade à atividade de operação no centro de controle existente - principal situação de referência analisada -, foram identificadas situações características do trabalho de operação, observando as variabilidades e estratégias adotadas pelos operadores. Assim, foi possível identificar situações como: 1) trocas de turno dos operadores, quando é necessário que dois ou mais operadores usem um console de operação ; 2) treinamentos de novos operadores, quando dois operadores operam de um mesmo console ; 3) abertura ou fechamento de tubulações, quando há uma comunicação mais intensa via telefone com os operadores de campo locais; e 4) situações de mau funcionamento de algum sistema, quando membros da coordenação e da gerência ficam dentro da sala de controle até a situação ser normalizada.

12 Em seguida, a partir das plantas baixas e das maquetes física e eletrônica (Figura 1) foram reconstituídos, junto aos operadores, esses principais cenários de funcionamento da sala de controle, introduzindo simulações que permitiram prever características do trabalho futuro. Foi possível, também, realizar simulações em tamanho e condições reais de trabalho (Figura 2), com a montagem de protótipos de consoles (estações de trabalho com dispositivos de vídeo, usadas na sala de controle) e de cubos do sistema de 
videowall (sistema de visualização gráfica formado por cubos modulares de retroprojeção unidos mecanicamente, constituindo uma única tela), instalados pelas empresas que participariam dos processos de licitação para fornecimento desses equipamentos. A montagem dos protótipos permitiu que os operadores, usuários do console, pudessem testar o mobiliário de operação. Esse teste foi realizado durante um turno de trabalho ( 8 horas). Parte desse teste foi gravada e serviu de base para autoconfrontação com o operador e avaliação do protótipo. Foram, ainda, testadas diferentes cadeiras para definição de um modelo que melhor se adequasse às atividades dos operadores, contribuindo para sua especificação final. Essas cadeiras tiveram uma utilização prolongada durante o teste a fim de que o operador pudesse comparar o desempenho das cadeiras depois de um turno de trabalho.

\section{FIgURA 1 : MAQUETES FÍSICA E ELECTRÔNICA}

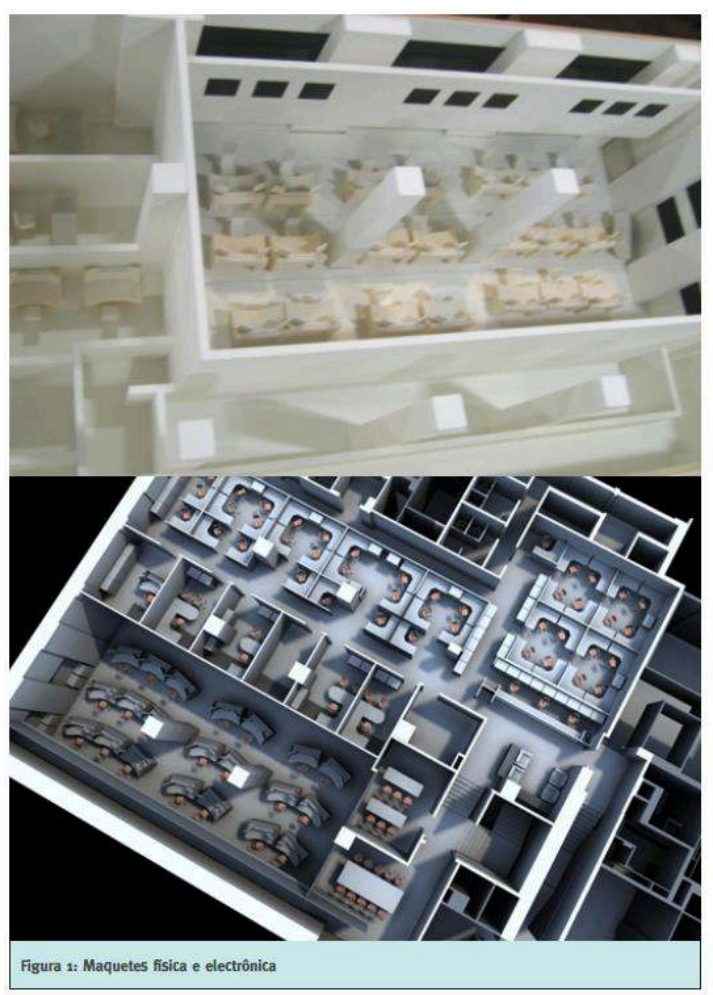


FIgURA 2 : SIMULAÇÃO DOS CONSOLES E DO VIDEOWALL

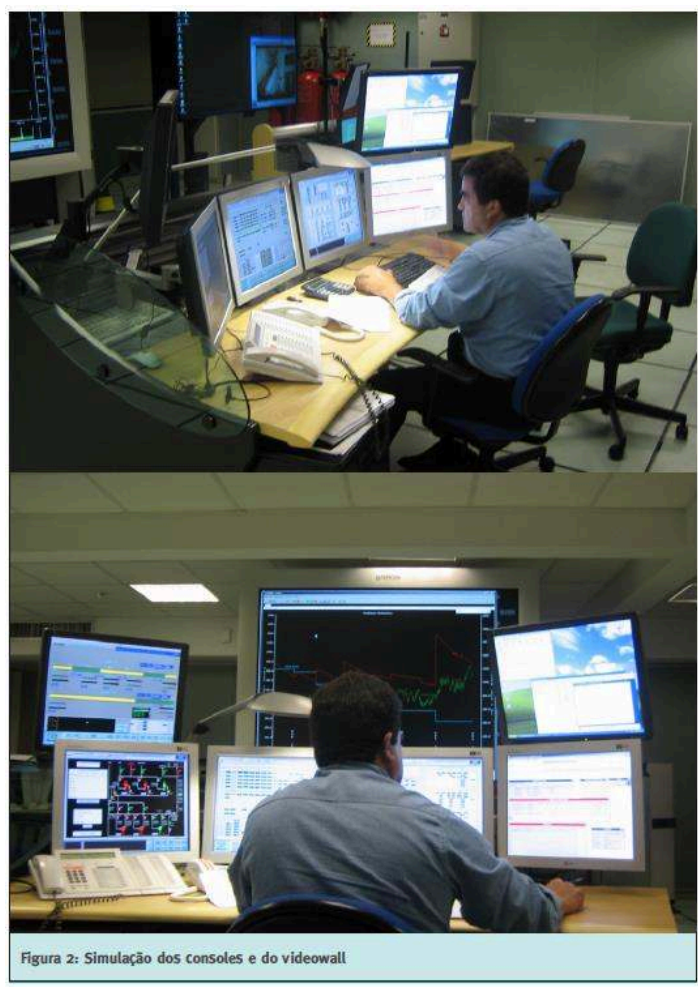

\section{A evolução do projeto do centro de controle}

O projeto usado como estudo de caso para este trabalho foi realizado a partir da solicitação de uma empresa de logística e transporte, com operação a nível nacional, que responde por atividades de transporte e armazenagem de petróleo e derivados, álcool e gás natural. A demanda apresentada pela diretoria da empresa foi de um projeto de ergonomia e arquitetura para modernização e realocação [5] do centro de controle existente, que passava a integrar em um mesmo espaço as equipes de controle de dutos de gás e óleo, sendo necessário ampliar a área ocupada e aumentar o efetivo de pessoal. O centro de controle de dutos supervisiona, comanda, controla e coordena as operações dos oleodutos e gasodutos, monitorando as variáveis de processo em tempo real e comandando equipamentos de forma remota. Essa operação é realizada 24 horas por dia, 365 dias por ano, a partir do edifício sede da empresa, no centro da cidade do Rio de Janeiro.

14 A proposta da solução arquitetônica foi então discutida e transmitida aos demais projetistas tendo por base as demandas identificadas com esses recursos de simulação, bem como as demandas dos demais usuários, identificadas através de entrevistas. No período de execução da obra, manteve-se a dinâmica de reuniões semanais, envolvendo a coordenação do projeto por parte da empresa, representantes da empresa contratada para a execução e representantes da equipe de ergonomia e arquitetura, além da realização de visitas periódicas ao canteiro de obras [ $\left.{ }^{6}\right]$.

15 A intervenção ergonômica foi marcada por dois aspectos que influenciaram os resultados e a gestão do processo de projeto : 1) a identificação e a ênfase dada à lógica da atividade de trabalho, que 2) contribuiu para animar as reuniões, onde os diversos 
envolvidos tiveram espaço para expor suas idéias, necessidades e restrições. Esses aspectos foram observados durante todo o processo, ficando evidentes em três situações :

a. na construção progressiva do programa de necessidades ;

b. na integração das necessidades dos diferentes projetistas ; e

c. na necessidade de se alterar soluções dadas em projeto durante a execução da obra.

O centro de controle existente funcionava em duas salas distintas - uma para o controle do gás e outra para o controle do óleo - além das áreas de apoio administrativo e técnico. Em virtude dos avanços tecnológicos que poderiam ser implementados, assim como o crescente aumento das malhas de dutos pelo país, surgiu a necessidade de ampliação e integração das operações de gás e óleo. Para a direção, seria também uma oportunidade de melhor divulgar suas atividades, por meio das tecnologias avançadas incorporadas aos sistemas de controle, às quais a sala de controle poderia dar uma visibilidade particular, sobretudo por estar localizada no edifício sede, que recebia visitas diversas, inclusive de clientes potenciais.

O espaço determinado para o projeto compreendia uma área com aproximadamente $1.275 \mathrm{~m}$, englobando parcialmente o pavimento térreo, o mezanino e o subsolo do edifício sede da empresa. $O$ escopo do projeto contemplava desde sua concepção até a elaboração de um projeto básico para licitação da etapa de execução da obra, abrangendo : 1) detalhamento dos espaços de trabalho, incluindo definição de layout, especificação de materiais, tratamento acústico, projeto de iluminação, especificação do mobiliário e comunicação visual; 2) definição de projetos complementares, como estrutura, ar condicionado, instalações elétrica, hidráulica e sanitária, sistema de segurança contra incêndio e pânico, e automação predial; e 3) acompanhamento da etapa de execução da obra.

Um projeto é um processo de transformação, cujo objetivo é satisfazer as necessidades e exigências dos atores envolvidos, havendo um conjunto de resultados a alcançar dentro de um prazo pré-estabelecido. Os projetos, geralmente, têm suas metas definidas em função de qualidade, custo e prazo. Neste, o prazo era o que tinha mais peso aos olhos da diretoria e se apresentou como determinante do seu desenvolvimento. No início, em abril de 2006, foi feito um planejamento considerando o prazo de cinco meses para o projeto e três meses para a execução da obra. Ao longo de seu desenvolvimento, entretanto, foram necessárias atualizações e alterações do cronograma definido inicialmente. Depois de várias adequações no cronograma, a entrega definitiva dos projetos de base ocorreu em outubro de 2006 ; a licitação para a execução da obra se estendeu por cindo meses, e a obra propriamente dita por outros cinco meses, sendo encerrada em agosto de 2007. A Figura 3 apresenta o cronograma geral do projeto, com suas etapas principais e os prazos programados e efetivamente realizados. 
Figura 3 : Cronograma : previsto e realizado Planejado inicialmente Realizado

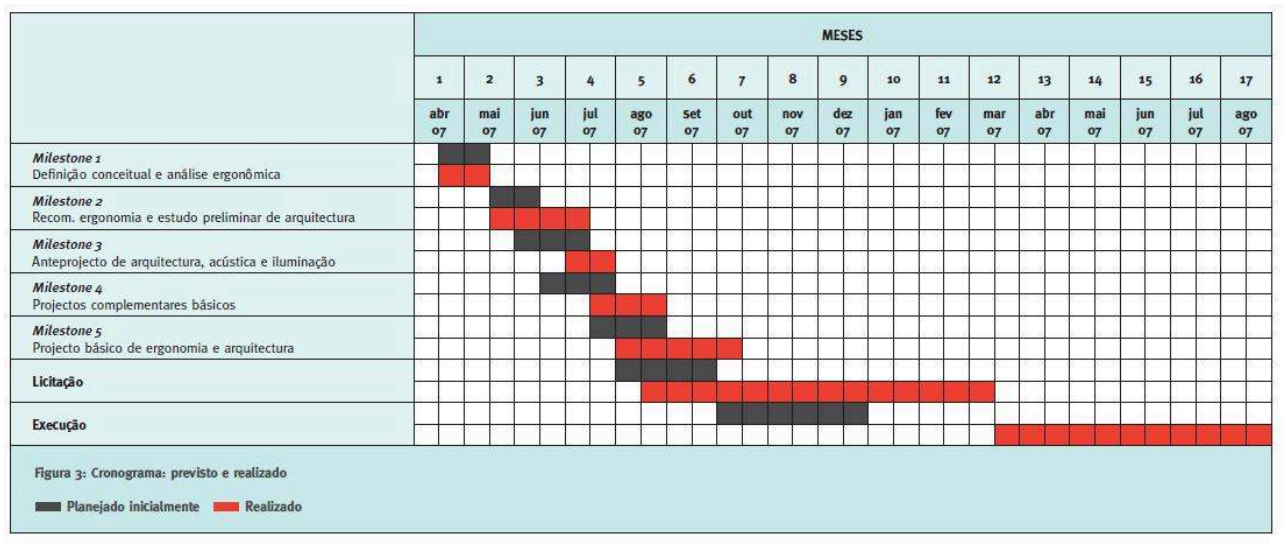

19 Ao longo do processo projetual, observou-se uma evolução das necessidades apresentadas inicialmente pela empresa e, consequentemente, das idéias e estudos de layout apresentados como possíveis soluções para o problema proposto. 0 projeto do centro de controle teve um planejamento de atividades, eventos de entrega e cronograma bem definidos. No entanto, algumas limitações e, principalmente, alguns fatores que surgiram ao longo do desenvolvimento do projeto, foram decisivos na sua evolução. Por tratar-se de um projeto para aproveitamento de um local pré-existente no edifício sede da empresa, foi necessário buscar soluções que reduzissem o impacto da restrição da área disponível face às demandas de espaço inicialmente apresentadas. Essas demandas precisaram ser revistas, assim como a própria área de projeto, que, por fim, acabou por sofrer uma ampliação em um dos pavimentos e uma redução em outro. Mesmo depois de aprovado o estudo preliminar, algumas alterações continuaram ocorrendo. Muitas dessas mudanças não poderiam ter sido, de fato, antecipadas, pois somente com a evolução do processo foi possível para os diversos atores da empresa manifestarem suas necessidades ao serem confrontados com as propostas materializadas em plantas e maquetes. Essas manifestações de diferentes usuários auxiliaram o processo decisório da direção a respeito do programa de ocupação do espaço e permitiram aos projetistas obter mais informações que se revelaram essenciais para reorientar as soluções de projeto. A seguir são destacadas algumas alterações que caracterizam essa evolução.

No pavimento térreo, em uma área de pé-direito duplo onde foi situada a sala de controle, o programa inicial, apresentado pela empresa, solicitava: uma sala de reunião, uma sala para situações de crise e espaços para equipamentos de ar condicionado, sanitários e refeitório. No decorrer do projeto, as demandas para algumas salas sofreram mudanças e o próprio partido arquitetônico adotado evoluiu, uma vez que aumentava a cada dia o conhecimento sobre as necessidades dos usuários e as linhas de força determinantes da situação. Depois de cerca de vinte estudos gerados e discutidos com os diferentes usuários, as salas de reunião e de crise deixaram de existir, surgindo as salas para os coordenadores de turno (COTURs da equipe de gás e de óleo) e a sala de simulação para a formação e treinamento dos operadores. Essas mudanças foram consequências de novas necessidades surgidas durante o processo projetual. Exemplo significativo está relacionado à função de coordenação de turno que, com o aumento dos postos de trabalho das equipes de operação, passava a ser considerado, efetivamente, uma função de coordenação de equipe e não mais uma 
função operacional como vinha ocorrendo. Essa mudança organizacional gerou, durante o projeto, a necessidade das salas dos coordenadores. Mesmo não fazendo parte do programa inicial, o layout final do pavimento térreo incluía, ainda, uma área de manutenção do videowall e uma área de circulação que permitisse acesso aos ambientes desse pavimento sem passagem pelo interior da sala de controle.

Na Figura 4 pode-se observar a evolução do layout do pavimento térreo : dos primeiros estudos ao layout final do projeto. Desde a primeira opção apresentada, a área com pédireito duplo foi destinada à sala de controle, visando maior amplitude para o espaço, como também permitir a visualização a partir do mezanino. Seguindo a demanda apresentada para o número de consoles, foram posicionados seis para a equipe do gás $\mathrm{e}$ quinze para a equipe do óleo. Na primeira opção (Figura 4A), os consoles das equipes do gás e do óleo foram dispostos em sentidos opostos, considerando dois sistemas de videowall posicionados nas extremidades da sala de controle - melhor posição do ponto de vista da iluminação para evitar reflexos e ofuscamento pelas esquadrias. Contíguas à sala de controle, foram posicionadas as salas de reunião e de crise. Nos estudos posteriores (Figura 4B), apesar de mantido o posicionamento da sala de controle na área de pé-direito duplo, foi adotada a premissa de integração entre as equipes de gás e óleo na sala de controle, optando-se por não posicionar os operadores de costas uns para os outros. Essa premissa partiu da solicitação da direção da empresa, que tinha por objetivo a futura integração das operações de gás e óleo. A sala de crise passou a ser uma sala destinada a treinamento dos operadores, uma vez que essa necessidade não havia até então sido contemplada mas se mostrava prioritária, mesmo não constando no programa inicial fornecido pela empresa; a escassez de espaço demandava uma priorização das diferentes necessidades.

FIgURA 4 : EVOLUÇÃo DAS OPÇõES DE LAYOUT PARA O PAVIMENTO TÉRREO

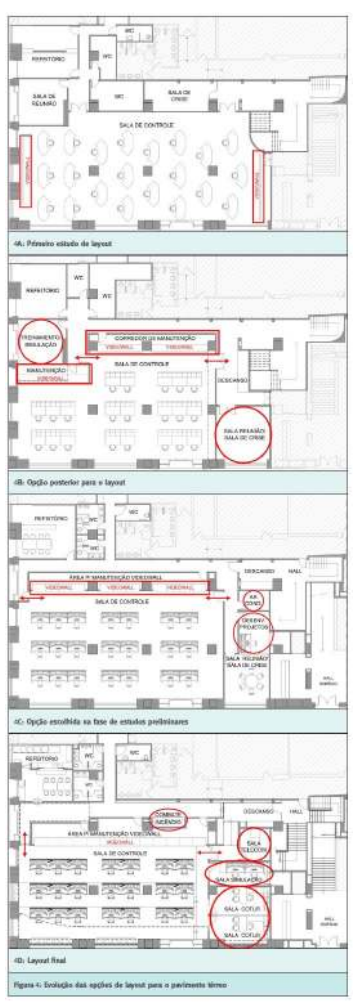


O desenvolvimento dos estudos levou a novas transformações representadas por três novos layouts apresentados para a diretoria da empresa. A análise das vantagens e desvantagens de cada opção levou à definição da opção escolhida (Figura 4C). Optou-se por um layout que apresentava circulação externa à sala de controle com acesso à sala de reunião, à área de manutenção do videowall e às áreas de uso comum. Essa área exclusiva para o sistema de videowall mostrou-se necessária por causa das constantes manutenções, regulagens e/ou trocas de lâmpadas esperadas para esse equipamento. Assim, um acesso externo à sala de controle minimizaria a interferência na atividade de operação, reduzindo o fluxo de pessoas na área de operação. Até a solução final do projeto (Figura $4 \mathrm{D}$ ), muitas foram as alterações de salas ao redor da sala de controle e do posicionamento dos consoles em seu interior, chegando-se à solução que compreendia : 1) as salas para os coordenadores de turno do gás e do óleo ;2) uma sala de treinamento/simulação ; 3) uma sala para os racks de telecomunicações, solicitada pelos técnicos da empresa ; 4) uma área para o posicionamento dos cilindros do sistema de combate a incêndio, solicitada pelo projetista desse sistema; e 5) o sistema de videowall que foi afastado dos pilares, reduzindo a área da sala de controle, mas unificando todos os cubos de visualização, o que ampliaria as possibilidades de utilização do sistema, além de facilitar a sua manutenção. Sanitários e refeitório para uso exclusivo dos operadores foram considerados em todas as opções.

De forma similar ao ocorrido no pavimento térreo, o projeto do mezanino passou por transformações significativas, sendo a principal delas o aumento da área. Logo no início dos trabalhos, constatou-se que a área disponibilizada era insuficiente para a demanda que previa quatro salas de coordenação e cinquenta e duas estações de trabalho, salas de reunião e treinamento, e espaços para equipamentos de ar condicionado, arquivo mestre e sanitários.

O ganho na área destinada ao projeto de cerca de $160 \mathrm{~m} 2$ não foi simples, demandando diversas negociações no interior da empresa entre suas diferentes diretorias. A solução encontrada foi a utilização um espaço ocioso sobre um auditório existente no pavimento térreo, viabilizada pela construção de uma laje suportada por estrutura metálica. Dessa forma, foi possível contemplar as demandas definidas inicialmente, bem como as novas necessidades surgidas no decorrer do projeto, com exceção de sete estações de trabalho alocadas em outro pavimento. Tudo se passa como se a pressão gerada pelos conflitos entre demandas que disputavam o mesmo espaço reorientasse a solução para ampliação das fronteiras externas, de modo a acomodar as necessidades reconhecidas como legítimas durante as negociações, mas que ainda não encontravam seu lugar.

Finalmente, os postos de trabalho das secretárias foram posicionados junto a um balcão de recepção próximo ao acesso principal ao centro de controle. Foram incluídas, ao longo do projeto, duas salas de reunião, uma ampla sala de visitas com visualização para a sala de controle, uma sala de desenvolvimento de projetos (utilizadas pela equipe de engenheiros e técnicos de automação) e uma sala para equipamentos de telecomunicações. A sala de treinamento, por sua vez, teve sua demanda de uso mais bem formulada, até que se chegasse ao layout final. Essa sala teria uso diferente da sala de simulação destinada ao treinamento na operação do sistema de controle. A sala de treinamento do mezanino seria utilizada para treinamentos corporativos das equipes de operadores e nela seriam instalados cerca de dez microcomputadores com acesso à rede interna da empresa. 


\subsection{A evolução do programa arquitetônico e as novas soluções adotadas}

O programa de necessidades, ou programa arquitetônico, tem finalidades diversas conforme os atores do projeto (Martin, 2000) : 1) para o cliente é uma referência ao longo de todo o processo ; 2) para os projetistas é uma base de trabalho ; 3) para os futuros usuários do espaço é a segurança de que suas demandas e especificações de funcionamento foram bem definidas; e 4) para todos é um meio de acompanhar e comparar o problema proposto e a resposta apresentada. Segundo Martin (2000), é através do programa que o cliente estabelece para os projetistas os objetivos e restrições do projeto. Porém, a realização do projeto necessita da reflexão sobre a organização futura do espaço, que será discutida entre os atores e contribuirá para o aprimoramento desse programa ao longo do processo. Para Guérin (1999), o programa deve descrever o "retrato do futuro", mas deve poder evoluir levando em consideração os eventos e o tempo transcorrido entre as perspectivas e a "materialização" desse futuro.

Durante o projeto houve uma evolução das necessidades apresentadas inicialmente pela empresa e, conseqüentemente, das soluções possíveis. A demanda inicial do projeto e dos ambientes partiu da diretoria. Sob essa lógica, o espaço a ser projetado deveria, além de considerar as exigências da operação em si, transmitir a imagem comercial da empresa - sólida, moderna e eficiente - para possíveis futuros clientes. $\mathrm{O}$ projeto começou a ser desenvolvido com base nessas definições. A AET realizada no centro de controle existente e as verbalizações dos operadores e coordenadores permitiram explicitar necessidades não consideradas inicialmente, o que levou à proposição de outras soluções : criação de novas salas e novos usos para algumas salas, como no caso do desmembramento da sala de treinamento em duas salas distintas (uma sala para treinamento corporativo dos operadores no mezanino, e uma sala para simulações e treinamento de operadores no uso do sistema operacional do centro de controle no pavimento térreo), mudanças de mobiliário, entre outras. A construção progressiva do programa arquitetônico foi marcada pela confrontação das lógicas dos usuários do centro de controle e dos projetistas.

Um exemplo de novas soluções para o espaço de trabalho resultantes dessa confrontação foi a solução adotada para a sala de visitas e as salas de reunião. Havia a solicitação da diretoria de uma sala de reunião, onde futuros clientes pudessem visualizar a área de operações, o que foi ponto de divergência. Gerentes e diretores queriam uma ampla visualização de toda a sala de controle pelos visitantes, com objetivo de divulgar a imagem de um moderno centro de controle a seus potenciais clientes ; os operadores, por sua vez, não gostavam da idéia de serem observados sem aviso prévio, com a alegação de comprometimento de sua privacidade no ambiente de trabalho. Durante as entrevistas e a AET, identificou-se a necessidade de mais uma sala de reunião, que não fazia parte da demanda inicial, para uso dos engenheiros e técnicos de apoio à operação, independente da sala para visitas. Posteriormente percebeu-se que apenas essa sala não atenderia a demanda, já que a sala disponível para reuniões no centro de controle existente recebia frequentemente mais de uma solicitação de uso para os mesmos horários. 
Dessa forma, optou-se pelo projeto de três salas distintas. A sala de visitas teve sua área e seu posicionamento alterados várias vezes no decorrer do estudo preliminar; a definição de seu uso foi discutida no decorrer de todo o processo até a definição final apresentada: uma sala com uma grande mesa de reunião, com possibilidade de projeção e de acesso ao sistema de operação, e com visibilidade para a sala de controle, além de ter acesso a uma "passarela" com ampla visualização de toda a área de operação, que amenizava a sensação de invasão de privacidade de que se queixavam os operadores. Além disso, essa solução otimizou a visão panorâmica da sala de controle, sem prejuízo da área reservada às demais salas de trabalho. No entanto, a decisão de manter as duas salas de reunião não se estabilizou mesmo após a identificação dessa necessidade. Incorporada ainda nos estudos preliminares, a segunda sala de reunião foi considerada e desconsiderada seguidamente ao longo do projeto, de acordo com a área disponível em cada opção desenvolvida. Essa segunda sala funcionava como um espaço de regulação dos conflitos internos ao projeto, por fugir ao padrão dos outros pavimentos que dispunham de apenas uma sala. Ao final, prevaleceu a solução que atendia a demanda dos usuários identificada com a AET.

A Figura 5 apresenta a evolução do projeto de layout do mezanino: A) o primeiro estudo com apenas uma sala de reunião ; B) o segundo estudo, já considerando a sala de visitas ; C) novo estudo apresentando a sala de visitas, uma sala de reunião, além de uma passarela para visualização da sala de controle - a partir desse estudo já estava sendo considerada a expansão da área destinada ao mezanino ; D) primeiro estudo com a sala de visitas integrada à passarela de visualização e com duas salas de reunião ; E) o estudo mantendo a sala de visitas com a passarela de visualização, mas novamente com apenas uma sala de reunião e F) o layout final voltando a apresentar as duas salas de reunião, mas posicionadas em uma nova área.

Figura 5 : Evolução das opções para as salas de visitas e reuniões no layout do mezanino

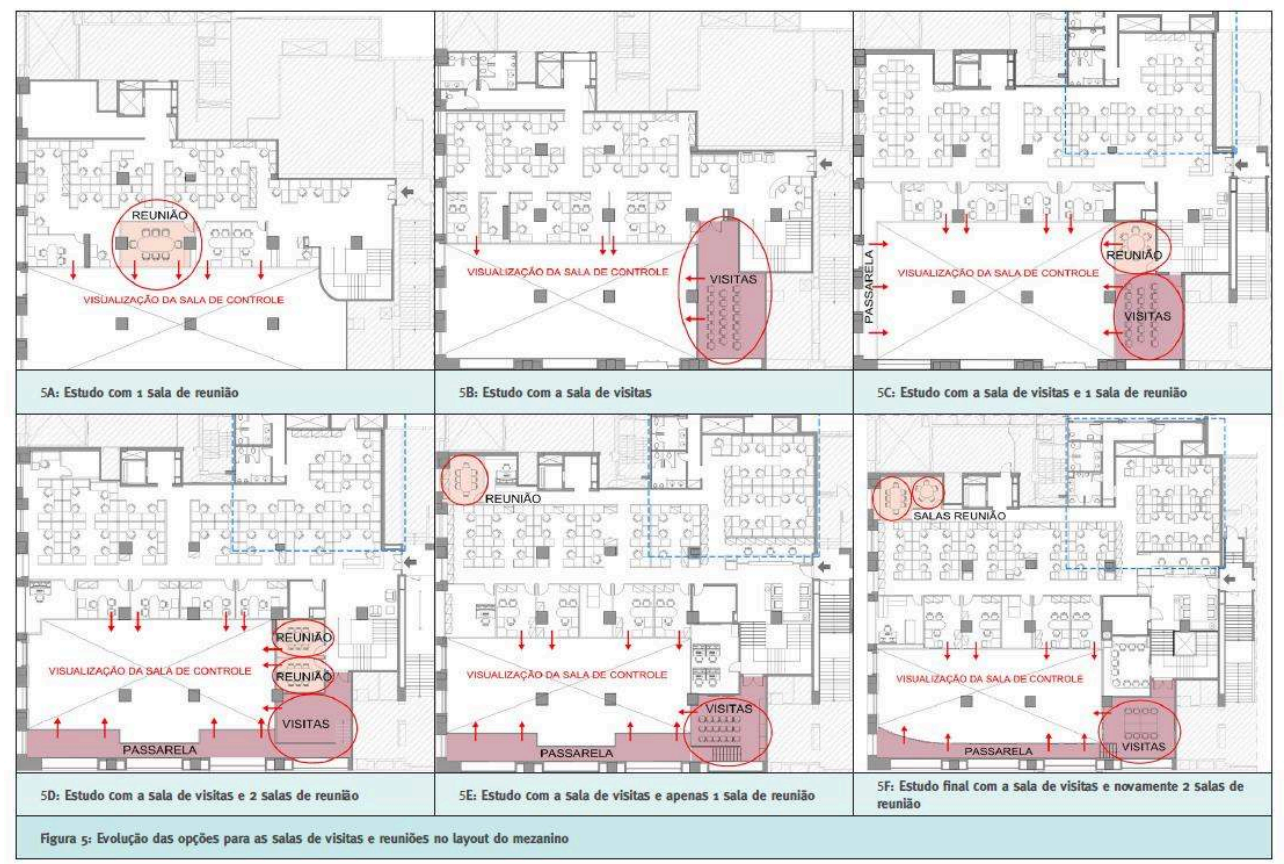

Laboreal, Volume 4 №2 2 | 2008 


\subsection{A Integração das necessidades dos diferentes projetistas durante a fase de projetos}

31 A intervenção ergonômica no projeto de espaços de trabalho procura fazer com que o processo de concepção seja considerado não como a resolução de um problema, mas como sua boa formulação, a partir da compreensão do comportamento dos trabalhadores durante a realização de suas tarefas. Para além do reconhecimento do ponto de vista da atividade dos usuários, a intervenção ergonômica contribui para a gestão e integração das diferentes lógicas envolvidas nesse processo - clientes, projetistas, trabalhadores/usuários etc. Uma intervenção global, que exige expressão, confrontação e interação entre diversos pontos de vista, muitas vezes divergentes ou contraditórios, ao invés de se estabelecer um consenso a priori é, segundo Guérin (1999), o caminho para o desenvolvimento eficaz de um projeto.

No projeto aqui relatado, a construção dos compromissos entre as lógicas dos diferentes projetistas envolvidos pode ser presenciada em diferentes momentos. As proposições iniciais de cada especialista foram alteradas através de negociações que ocorreram nas reuniões de trabalho durante todo o projeto. Cada especialidade profissional possui necessidades específicas, o que exige definições de projeto para atendê-las. Algumas dessas necessidades foram apontadas nas etapas iniciais, enquanto outras só surgiram durante o desenvolvimento dos projetos de base, ou ainda quando os projetos específicos começaram a ser compatibilizados e suas interferências identificadas. É ao longo do desenvolvimento do projeto, quando existe, de fato, a transformação da idéia em realidade, que há uma evolução na quantidade de informações e decisões (Salgado, 2004). Alguns exemplos demonstram a dinâmica e as soluções dadas de forma a atender às diversas demandas dos diferentes projetos complementares.

No mezanino, a altura entre as lajes de piso e teto era pequena, assim, as alturas do pédireito e, consequentemente, do entre-forro e do entre-piso, foram discutidas exaustivamente nas reuniões com os projetistas complementares desde o anteprojeto, chegando-se a uma definição somente durante o desenvolvimento do projeto básico. Houve um impasse em relação às necessidades apresentadas : a equipe de arquitetura tinha por objetivo que o pé-direito fosse o mais alto possível, visando manter o ambiente final com proporções que evitassem a sensação de confinamento ; a projetista de iluminação também necessitava de um pé-direito elevado para obter uma adequada distribuição de luz ; a projetista de acústica, por sua vez, precisava de altura de entreforro para instalação de um sistema de mascaramento acústico, o que reduzia o pédireito ; os projetistas de elétrica e automação necessitavam de altura no entre-piso para passagem de eletrodutos e cabeamentos (cabos), também reduzindo o pé-direito. A solução adotada, depois de várias proposições e discussões, foi a redução ao mínimo da altura do entre-piso com o uso de calhas mais baixas para o cabeamento, e a encomenda de unidades do sistema de mascaramento diferenciadas em relação à altura padrão, permitindo reduzir o entreforro. Essas soluções parciais, somadas, proporcionaram um pé-direito de 2,40 metros, que permitia acomodar as demandas da equipes de arquitetura e luminotécnica. Essa solução foi viabilizada também pela adequação do projeto de climatização a essa limitação de alturas, posicionando os dutos de insuflamento apenas sobre os espaços de circulação, que ficaram com pé-direito reduzido $(2,15 \mathrm{~m})$. 
Outro exemplo da integração das necessidades dos diferentes projetistas ocorreu durante a definição do layout, mais especificamente, na alocação de áreas para as máquinas de climatização e os equipamentos de telecomunicações. Inicialmente foi prevista uma sala para os equipamentos de ar condicionado em cada pavimento do centro de controle. Posteriormente, durante o desenvolvimento dos primeiros estudos, foi identificada a necessidade de salas também para os equipamentos de telecomunicações. Além disso, ao conhecer mais os espaços destinados ao centro de controle e visando reduzir a passagem de dutos, o projetista de climatização reposicionou suas salas de equipamentos passando a ter duas no mezanino e nenhuma no térreo. Esse rearranjo de salas gerou novos estudos de layout face às restrições de espaço destinados aos operadores e equipes de apoio em todos os pavimentos.

\subsection{As alterações durante a execução da obra e seus impactos sobre a atividade futura}

35 Conforme Cordeiro (2003), a etapa de execução de uma obra não consiste exclusivamente na realização do que foi decidido na dita etapa de projeto. Ao contrário, a construção é marcada fortemente pela continuidade das atividades de concepção da solução do espaço que está sendo construído, seja desenvolvendo aspectos ainda não detalhados, seja reconcebendo e adaptando idéias prévias, o que a torna mais complexa do que habitualmente é pensada.

36 A etapa de construção do projeto aqui apresentado foi marcada por diversas alterações nas soluções construídas pelos projetistas, tais como: substituições de materiais especificados por outros de menor custo e considerados similares; simplificações de detalhes construtivos a fim de facilitar o trabalho de execução; desenvolvimento de soluções ainda não detalhadas; modificações de projeto a fim de atender novos objetivos e demandas. As alterações foram desde pequenos ajustes para adequar o projeto às condições reais do canteiro de obras até mudanças de layout, que desencadearam alterações em cascata nos projetos complementares.

Por causa dos constrangimentos de prazo, custo e qualidade vividos pelos novos participantes do projeto - os construtores -, essa etapa foi marcada fortemente por confrontações entre os projetistas e os responsáveis pela execução da obra. A construção de compromissos com a lógica da atividade de operação enfrentou dificuldades, já que o trabalho focado pelos responsáveis pela obra não era o trabalho futuro da operação, e sim as atividades de trabalho que estavam sendo realizadas no canteiro de obras. Dificuldades desconhecidas foram colocadas em cena, sustentadas por atores que ainda não haviam se manifestado durante o projeto. Com a obra em andamento, as decisões e negociações pareciam mais difíceis e, em alguns casos, irreversíveis, por causa de decisões tomadas em esferas distantes do nível mais operacional.

38 A necessidade de modificações das soluções que ocorre na etapa de execução, reflexo em parte da ausência de uma estrutura adequada para integrar a execução à construção social das etapas iniciais de projeto, agravada pelo prazo rígido e apertado para o término da obra, acabam por impactar [ $\left.{ }^{7}\right]$ o resultado final esperado. Durante a fase de demolições na obra, por exemplo, surgiram alguns imprevistos não considerados no projeto básico. Como se tratava de uma obra em edifício antigo, vigas, pilares, desníveis e tubulações só puderam ser verificados na etapa de demolições, já que não havia uma 
documentação atualizada com os projetos das diferentes instalações e de estrutura construídas. Algumas interferências com o projeto básico foram identificadas e algumas alterações se fizeram necessárias, com efeitos sistêmicos, gerando mudanças em diversos projetos. Assim, uma avaliação mais global, considerando as interferências de cada mudança e suas inter-relações, seria fundamental nesses momentos de reconcepção. Porém, face às restrições de prazo, a identificação dos problemas aconteceu de maneira isolada, sem tempo hábil para repensar as soluções de forma global, envolvendo todas as especialidades.

Um dos problemas identificados na fase de demolições, e que gerou mais impactos sobre o projeto, foi a localização de uma caixa de instalação elétrica junto ao teto do mezanino. Essa caixa, que não poderia ter seu posicionamento alterado, estava situada sobre uma das circulações da área de escritórios, por onde passava o duto de ar condicionado. Diante dessa situação, o posicionamento desse duto teve que ser alterado, caso contrário o pé-direito da circulação ficaria inferior a dois metros. Depois de alguns estudos e reuniões com os projetistas envolvidos, optou-se por rebaixar outra circulação da área de escritórios, mantendo-se o pé-direito previsto sobre as estações de trabalho. Diversas adequações foram necessárias nesse caso : 1) no próprio projeto de climatização, que precisou ser recalculado ; 2) no projeto de iluminação, que teve o posicionamento e o tipo de algumas luminárias alterados ; 3) na paginação das placas do forro no teto ; e 4) no layout, diante da circulação rebaixada e da introdução de uma nova divisória.

As alterações de materiais, provocadas, por um lado, devido ao objetivo de redução de custo e, por outro, devido à dificuldade de execução, impactaram de maneira importante o projeto desenvolvido. Após diversas alterações nas especificações dos materiais e soluções construtivas feitas pela empresa executante, com a aprovação da empresa contratante a fim de agilizar a finalização da obra, constatou-se que o tratamento acústico previsto para essa área não tinha sido executado em sua íntegra. Faltavam, principalmente, a aplicação de materiais absorventes em várias superfícies e as vedações previstas para as esquadrias da fachada, o que resultou em um nível de ruído interno relativamente elevado e inadequado à atividade de operação, com características essencialmente cognitivas. As queixas relativas ao resultado acústico da área de operação foram muitas e demandaram correções ainda em curso. Apesar do projeto acústico ser um dos focos de atenções e cuidados especiais durante a fase de projetos, demandando a construção de soluções originais, a sua execução teve impacto negativo importante sobre o resultado esperado.

41 As transformações do projeto de acústica tiveram início com a substituição do forro acústico, provocada pelo custo, considerado elevado, do material originalmente especificado. Essa substituição envolveu negociações entre várias disciplinas face ao impacto desse material para a estética e para a qualidade lumínica e acústica do ambiente construído. $O$ teto é, normalmente, uma das principais áreas de absorção de ruído e a redução nos níveis de absorção poderia inviabilizar o uso do sistema de mascaramento acústico.

Outra questão que gerou impactos no projeto acústico foi a execução das esquadrias, especificadas com um sistema de vedação para minimizar a entrada de ruídos externos. Face à localização do centro de controle, no pavimento térreo de um edifício no centro da cidade do Rio de Janeiro, houve a necessidade de utilização de vidro a prova de balas, com cerca de $5 \mathrm{~cm}$ de espessura e, portanto, muito pesado. Dessa forma, a execução da 
vedação das esquadrias com esses vidros foi dificultada. Como só houve a identificação desses problemas no canteiro de obras, ficou reduzida a margem de manobra para solucioná-los, provocando prejuízos para a acústica do ambiente construído, que teria sido mais eficaz caso a vedação tivesse sido feita em sistema de pré-montagem pelo próprio fornecedor das esquadrias.

\section{Discussão}

O desenvolvimento do processo de concepção (projeto e execução) de um espaço de trabalho, tal qual qualquer outra atividade de trabalho, na prática, não é linear ; não segue estritamente o que foi planejado em decorrência de imprevistos que surgem em seu desenrolar, exigindo alterações das prescrições iniciais. É apresentada uma demanda pelo cliente, a partir da qual são expressos seus desejos e aspirações em relação ao projeto ; porém, nem o cliente, nem os projetistas sabem com exatidão todas as necessidades a serem atendidas pelo espaço a ser construído, algumas das quais surgem ao longo do projeto, com o crescente esclarecimento sobre a função do espaço, as restrições, as possíveis soluções arquitetônicas e sobre as atividades de trabalho que nele serão realizadas.

A introdução da lógica do trabalho, evidenciada pela ação ergonômica, permite a criação de novas soluções para o espaço, a partir da ampliação do escopo do programa arquitetônico e da confrontação das diversas lógicas envolvidas no processo. Por outro lado, a criação de espaços de confrontação e a busca de compromissos entre os atores do projeto, cada qual com interesses e lógicas particulares, influencia a gestão do processo de projeto, sendo necessário prever uma estrutura organizacional para suportar a dinâmica de reuniões, as simulações etc.

45 A intervenção aqui apresentada teve como base a abordagem da ergonomia da atividade profissional (Daniellou \& Béguin, 2007). Nessa abordagem, uma etapa-chave para compreensão dos problemas e construção das soluções foi a análise de situações reais de trabalho e o envolvimento de usuários com o projeto em curso. A análise da atividade e a utilização de técnicas de simulação permitem a antecipação de diversos problemas das situações futuras, e isso desde as etapas iniciais dos projetos. Apesar dos autores de gestão considerarem que no início pouco se sabe sobre o resultado final de um projeto específico (Midler, 1995), a abordagem da ergonomia da atividade aplicada na concepção de situações de trabalho vem demonstrando que essa lacuna pode ser reduzida. A concepção é um processo de trabalho em grupo, que articula diferentes perspectivas, experiência e interesses. Nenhum ator isoladamente dispõe de uma representação de todos os problemas e possui competências para resolvê-los. Nas sociedades modernas, tenta-se reduzir a complexidade diferenciando as tarefas e distribuindo-as a diferentes atores em função de suas competências especializadas. Paradoxalmente, esse princípio é fonte de uma nova complexidade. Qualquer que seja o objeto a ser concebido, ele não pode ser pensado com uma simples justaposição de sistemas técnicos: é necessário integrar as diferentes partes e para isso os atores devem se coordenar. Entretanto, com a grande diversidade de atores e objetivos distintos, os desacordos e conflitos são a regra. A eficácia específica da ergonomia manifestou-se com mais evidência no caso da integração dos projetos elétricos e de ar condicionado, cuja solução levou ao reposicionamento e re-projeto das instalações, de início consideradas tecnicamente inadequadas, de modo a preservar o pé-direito 
elevado e, consequentemente, o conforto dos operadores. Da mesma forma, a análise do trabalho e a participação dos operadores nas simulações e testes realizados permitiram contribuir para: 1) o dimensionamento dos consoles para a utilização de dois operadores, situação que ocorre nas mudanças de turno e no treinamento de novatos; 2) na disposição relativa dos diferentes consoles em função da interdependência entre os sistemas e as comunicações entre os operadores ; 3) na disposição dos sistemas de controle entre os diferentes monitores de cada console; e 4) na criação de salas de apoio ao trabalho coletivo, tais como as salas de reunião, de treinamento, de simulação e outras.

Ao longo do projeto surgem situações dinâmicas que interagem entre si e, em um processo cíclico de escolhas, são administradas as interfaces entre os atores da concepção e integradas suas demandas, tendo como resultado uma dada definição arquitetônica do espaço de trabalho. Essas escolhas não ocorrem sem restrições, são marcadas por limites próprios de cada projeto - em especial, a área disponível para o projeto, os prazos e os custos. Assim, entre o inicialmente desejado e o possível, as diferenças são evidentes e demandam uma estrutura de gestão capaz de compatibilizar as diferentes restrições e necessidades.

Nesse contexto, dois papéis distintos do ergonomista podem representar fontes de soluções inovadoras nos projetos, na medida em que aproximam o usuário do projeto. Em primeiro lugar o ergonomista é um ator da concepção como vários outros projetistas, porém ainda sem muita tradição e com um status mais fraco do que engenheiros e arquitetos. Ele mobiliza conhecimentos gerais da disciplina e conhecimentos específicos construídos na análise de situações de referência. No entanto, a característica integradora da atividade de trabalho, da qual o ergonomista passa a ser conhecedor, aproxima a ação da ergonomia do gerenciamento do projeto. Assim, conforme Béguin (2007), podemos falar de um segundo papel do ergonomista : influenciar a gestão dos projetos, criando espaços de confrontação de conhecimentos dos usuários e dos projetistas. Vários exemplos mostram que os principais problemas de condições de trabalho encontrados pelos operadores são relativos à falta de coerência e compatibilidade entre as diferentes áreas de conhecimento e disciplinas envolvidas no projeto (arquitetura, climatização, elétrica, automação etc.). O ergonomista se interessa pelo sistema como um todo e não por suas partes, o que o conduz a criar espaços de negociação e de decisão de maneira a alimentar confrontações entre lógicas contraditórias. Assim, podemos dizer que os ergonomistas trazem para os projetos essa dimensão sistêmica, evidenciando conflitos de interface entre as partes que o constituem e fornecendo elementos que permitem a antecipação de problemas futuros.

48 A etapa de execução da obra é chave para a qualidade do ambiente construído, o que nos convida à reflexão sobre como integrá-la, de fato, ao processo de projeto. Como as atividades de concepção têm continuidade nessa etapa, torna-se necessário organizar a execução para a concepção, ou seja, é preciso ter disponível uma equipe para construir respostas rápidas que conduza as modificações necessárias nas soluções dadas previamente para o espaço que está sendo construído e antecipem as repercussões para os diferentes subprojetos. Essa equipe de acompanhamento da obra acaba por desempenhar o papel típico de uma equipe de concepção, que, de maneira geral, não é prevista para a etapa de execução. Sua composição deveria integrar os diversos saberes 
envolvidos no projeto, para que as soluções escolhidas possam ser repensadas sob o ponto de vista das suas diversas necessidades e restrições.

Na fase de execução de um projeto, não basta supervisionar o que está sendo executado, apontando ao cliente não-conformidades entre projeto (solução idealizada) e obra (realidade concreta) e suas possíveis consequências sobre a atividade futura de trabalho. Essa posição de supervisão não garante que as soluções finais adotadas levem em consideração as premissas de projeto assumidas na fase anterior, nem o ponto de vista da atividade de trabalho futura. É preciso reestruturar todo o processo de projeto, desde o seu início, para as atividades de concepção que terão continuidade durante a execução da obra.

Cabem, finalmente, algumas questões sobre a prática da ergonomia em projetos. Os critérios principais de um projeto como qualidade, custo e tempo, passam a ser condicionantes e critérios internos para a ação ergonômica em projetos? A qualidade parece ser o critério onde a contribuição da ergonomia é a mais visível. No entanto, torna-se ainda necessário a articulação com custos e prazos. A redução dos custos totais e dos prazos globais de projeto parece estar intimamente relacionada à capacidade de desenvolvimentos de competências na área de simulação, o que ainda se encontra em desenvolvimento se comparado com outras disciplinas de projetos como as diferentes engenharias. Além disso, no início do projeto, os métodos de ergonomia demandam tempo para a análise das situações de referência; poderíamos então falar em perder tempo no início para ganhar mais à frente no projeto como um todo ?

51 A intervenção ergonômica já avançou no sentido da antecipação de problemas durante a fase de concepção, mas a reconcepção das soluções iniciais, sempre presente na etapa de execução, também requer uma avaliação pelo conjunto dos atores, reconsiderando a cada passo as implicações em diferentes aspectos do projeto, no interior de um espaço social de negociação permanente. Nesse caso, já não se trata somente de antecipar problemas futuros, mas também de resolver problemas que se colocam de imediato, sob pressão de tempo e custo.

\section{BIBLIOGRAFIA}

Béguin, P. (2007). O ergonomista : um ator da concepção. In Pierre Falzon (Ed.), Ergonomia (pp. 303-315). São Paulo : Editora Blücher. Boutinet, J. (2002). Antropologia do Projeto. Porto Alegre : Artmed Editora.

Conceição, C. (2007). A Prática de Projetos : O Caso de um Centro de Controle. Dissertação de Mestrado, Programa de Engenharia de Produção da COPPE/UFRJ, Rio de Janeiro.

Cordeiro, C. (2003). Entre o Projeto e o Uso : A Colaboração da Ergonomia na Etapa de Execução da Obra. Tese de Doutorado, Programa de Engenharia de Produção da COPPE/UFRJ, Rio de Janeiro.

Daniellou, F. (1988). L'Ergonome et les Acteurs de la Conception. In Actes de la XXIX Congrès de La Société d’Ergonomie de Langue Française, vol. 1 (pp. 27-32). Paris : Maison de la Chimie. 
Daniellou, F. (1992). Le Statut de la Pratique et des Connaissances dans l'Intervention Ergonomique de Conception. Thèse d'Habilitation en Ergonomie, Université Le Mirail, Toulouse.

Daniellou, F. (2004). Questões epistemológicas levantadas pela ergonomia de projeto. In François Daniellou (Coord.), A ergonomia em busca de seus princípios (pp. 181-198). São Paulo : Editora Edgar Blücher.

Daniellou, F. (2005). The French-speaking Ergonomists' Approach to Work Activity : Crossinfluences of Field Intervention and Conceptual Models. Theoretical Issues in Ergonomics Science, 6, (5), 409-427.

Daniellou, F. (2007). A Ergonomia na Condução de Projetos de Concepção de Sistemas de Trabalho. In Pierre Falzon (Ed.), Ergonomia (pp. 303-315). São Paulo : Editora Blücher.

Daniellou, F. \& Béguin, P. (2007). Metodologia da Ação Ergonômica : Abordagens do Trabalho Real. In Pierre Falzon (Ed.), Ergonomia (pp. 281-301). São Paulo : Editora Blücher.

Granath, J. (1991). Architecture, Technology and Human Factors : Design in a Socio-Technical Context. PhD Thesis, School of Architecture of Chalmers University of Technology, Göteborg.

Guérin, F. (1999). De l'Idée au Concret, un Enjeu de Cohérence pour l'Usage Attendu. In Actes de la Journée Conception Architecturale

- Entre Volonté Politique et Faisabilité Technique (pp. 15-22). Bordeaux : Laboratoire d'Ergonomie dês Systèmes Complexes, Université Victor Segalen Bordeaux 2.

Hippel, E. (1988). The Sources of Innovation. Oxford : University Press.

Martin, C. (2000). Maîtrise d'Ouvrage Maîtrise d'Oeuvre : Construire un Vrai Dialogue - La Contribuition de l'Ergonome à la Conduite de Projet Architectural. Toulouse : Octarès Éditions.

Martin, C., Ledoux, E., Escouteloup, J. \& Daniellou, F. (1995). Ergonomic Practice in Architectural Design Processes : What is at Stake in Initial Steps. In : Proceedings of the IEA World Conference, Brasil, pp. 187-190.

Midler, C. (1995). O automóvel que Não Existia : Gestão de Projectos e Transformação da Empresa. Lisboa : Monitor.

Salgado, M. (2004). Produção Arquitetônica e Interdisciplinaridade : Uma Discussão sobre o Processo de Projeto e a ISO 9001/2000. In Anais do X Encontro Nacional de Tecnologia do Ambiente Construído - CD-ROM. São Paulo.

Schön, D. (1983). The Reflective Practitioner : How Professionals Think in Action. New York : Basic Books.

Silva, V. (2000). O Processo de Produção de um Empreendimento Imobiliário : Uma Discussão sobre a Regulação da Distância entre Concepção e Execução. Dissertação de Mestrado, Departamento de Engenharia de Produção da UFMG, Belo Horizonte.

Vanni, C. (1999). Análise de Falhas Aplicada à Compatibilidade de Projetos na Construção de Edifícios. Dissertação de Mestrado, Departamento de Engenharia de Produção da UFMG, Belo Horizonte.

\section{NOTAS}

1. Utilizadores

2. Mudança na concepção anterior do projeto 
3. Tubulações (tubos) que conduzem ar (para climatização), gás ou óleo (combustíveis)

4. Solicitação, necessidade

5. Estaleiro das obras

6. Transferência para um novo local

7. Causar efeitos positivos ou negativos

\section{RESUMOS}

O objetivo deste trabalho é apresentar e caracterizar a contribuição da ergonomia para projetos de espaços de trabalho. A reflexão sobre a prática do projeto de um centro integrado de controle permitiu evidenciar que a articulação e compatibilização entre as necessidades dos diferentes usuários [1] e projetistas está na origem das inovações presentes nas soluções implantadas. A intervenção ergonômica na concepção dos espaços de trabalho mostra que o programa arquitetônico não define completamente o que querem os usuários. Essa definição é progressiva e enriquecida pela análise ergonômica do trabalho. Da mesma forma, a etapa de execução da obra é uma etapa de reconcepção [ [2] e de revisão de decisões anteriores. Nessa etapa, a intervenção ergonômica instrui as novas decisões, criando espaços de confrontação das diferentes lógicas e racionalidades envolvidas.

El objetivo de este trabajo es presentar y caracterizar la contribución de la ergonomía para proyectos de espacios de trabajo. La reflexión sobre la práctica del proyecto de un centro integrado de control evidenció que la articulación y compatibilización entre las necesidades de los diferentes usuarios y proyectistas está en el origen de las innovaciones presentes en las soluciones implantadas. La intervención ergonómica en la concepción de los espacios de trabajo muestra que el programa arquitectónico no define completamente lo que quieren los usuarios. Esa definición es progresiva y enriquecida por el análisis ergonómico del trabajo. De la misma manera, la etapa de ejecución de la obra es una etapa de reconcepción y de revisión de decisiones anteriores. En esa etapa, la intervención ergonómica instruye las nuevas decisiones, creando espacios de confrontación de las diferentes lógicas y racionalidades involucradas.

L'objectif de ce texte est de présenter, et de caractériser l'apport de l'ergonomie pour la conception des espaces de travail. L'analyse de la conception d'un centre intégré de contrôle montre que le fait d'articuler et d'intégrer les besoins des différents utilisateurs et des concepteurs est à l'origine de nombreuses innovations dans les solutions finalement retenues. Cette intervention ergonomique dans la conception des espaces montre que le programme architectural ne définit pas complètement ce que veulent les utilisateurs. Cette définition s'effectue progressivement, et elle est enrichie par l'analyse du travail. De plus, la construction est une étape de révision, et même de re-conception des décisions antérieures. En créant des espaces de confrontation des différentes logiques et des rationalités qui sont à l'oeuvre dans le projet, l'intervention ergonomique instruit les nouvelles décisions.

The purpose of this work is to present and characterize the contribution of ergonomics to workplace design projects. Reflecting on the practice of a design project of an integrated control centre allowed us to highlight that the articulation and process of checking compatibility among the needs of different users and designers is at the origin of the innovations present in the implemented solutions. Ergonomic intervention in the workplace design shows that the 
architectural programme does not entirely define what is required by the users. This definition is progressive and enriched by ergonomic analysis of the work. In a similar way, the execution stage of a construction is a stage of re-conception as well as one of revising previous decisions. At this stage, the ergonomic intervention leads to new decisions, creating spheres of discussion among the different logics and foundations involved.

ÍNDICE

Keywords: design process, ergonomics and architecture, workspaces, control room

Palabras claves: proceso de proyecto, ergonomía y arquitectura, sitios de trabajo, sala de control

Palavras-chave: processo de projeto, ergonomia e arquitetura, espaços de trabalho, sala de controle

Mots-clés: processus de conception, ergonomie et architecture, espace de travail, salle de contrôle

\section{AUTORES}

\section{FRANCISCO DUARTE}

Programa de Engenharia de Produção COPPE/ Universidade Federal do Rio de Janeiro Caixa postal 68507, CEP 21945-972, Rio de Janeiro, Brasil duarte@pep.ufrj.br

\section{CAROLINA CONCEIÇÃO}

Programa de Engenharia de Produção COPPE/ Universidade Federal do Rio de Janeiro Caixa postal 68507, CEP 21945-972, Rio de Janeiro, Brasil

carolina@pep.ufrj.br

\section{CLÁUDIA CORDEIRO}

Programa de Engenharia de Produção COPPE/ Universidade Federal do Rio de Janeiro Caixa postal 68507, CEP 21945-972, Rio de Janeiro, Brasil

claudia@gigalink.com.br

\section{FRANCISCO LIMA}

Universidade Federal de Minas Gerais Av. Antônio Carlos, 6627, CEP 31270-901, Belo Horizonte, Brasil

fpalima@ufmg.br 